Mots. Les langages du politique

$69 \mid 2002$

Révolutions

\title{
Antoine de Baecque, Les éclats du rire. La culture des rieurs au XVIIIème siècle
}

Jacques Guilhaumou

\section{OpenEdition}

Journals

Édition électronique

URL : https://journals.openedition.org/mots/10743

DOI : $10.4000 /$ mots. 10743

ISSN : 1960-6001

\section{Éditeur}

ENS Éditions

\section{Édition imprimée}

Date de publication : 1 juillet 2002

Pagination : 156-159

ISBN : 2-84788-011-9

ISSN : 0243-6450

\section{Référence électronique}

Jacques Guilhaumou, «Antoine de Baecque, Les éclats du rire. La culture des rieurs au xvilème siècle », Mots. Les langages du politique [En ligne], 69 | 2002, mis en ligne le 14 mai 2008, consulté le 23 avril 2022. URL : http://journals.openedition.org/mots/10743 ; DOI : https://doi.org/10.4000/mots.10743 
dignité » ou encore « immigration et intégration » vont se dessiner dans le fil même des débats les limites entre les deux camps. Cette partie s'achève sur l'exposé d'une " construction identitaire » fondée pour la Gauche sur le " droit à la différence » associé au " devoir d'accueil », et reposant pour la Droite sur le refus de «l'altération de l'identité française $»$.

La dernière partie offre un corpus à la fois riche et représentatif (80 pages, soit deux séances au Sénat). Ces textes permettent au lecteur de reconstituer (à partir de transcriptions qui ne reflètent qu'une vision policée des propos réellement tenus) le fil du débat et le jeu des enchainement discursifs.

L'ouvrage de F. Cabasino constitue une contribution originale à l'analyse des discours parlementaires.

Dominique Desmarchelier

Antoine de BAECQUE, Les éclats du rire. La culture des rieurs au XVIIIème siècle, Paris, Calmann-Lévy, 2000.

Après avoir étudié les représentations du corps en révolution ( $L e$ corps de l'histoire. Métaphore et politique (1770-1800), Calmann-Lévy, 1993 ) à partir de l'autoreprésentation politique d'une société, puis l'univers symbolique des cadavres politiques en 1'An II (La gloire et l'effroi, Grasset, 1997), sur le modèle de la sublime abjection déployée de manière spectaculaire au cours de la mort de Marat, Antoine de Baecque aborde un aspect encore mal connu d'une culture des Lumières dont il nous a récemment proposé une synthèse (Histoire culturelle de la France, tome 3, Lumières et liberté, Le Seuil, 1998), la culture des rieurs. L'étude des modalités d'émergence d'un âge du rire républicain clôt ainsi provisoirement un parcours fondateur d'une nouvelle histoire culturelle.

De cette « guerre du rire » généralisée au cours du $18^{\mathrm{e}}$ siècle, il ressort une grande diversité d'itinéraires de sociétés, de lignées ou de personnalités que l'auteur s'efforce de retracer sur la base d'une connaissance exhaustive des sources imprimées, journaux compris, conservées à la Bibliothèque nationale de France en la matière. Trois genres comiques dominent ici : le « bel esprit» des calotins, puis des persifleurs, le « langage populaire » de la farce grotesque inscrite dans la tradition burlesque, enfin « la gaieté de l'esprit français » devenue "gaieté nationale » avec la Révolution française. Mais une telle étude ne constitue 
pas un exercice d'analyse littéraire, loin de là. La méthode historique de l'auteur s'inscrit dans la nouvelle histoire culturelle. Elle rend donc d'abord compte de l'expérience comique telle qu'elle se raconte dans les textes (et non dans les images comme dans ses précédents ouvrages), histoire réflexive par excellence. Puis à partir des énoncés retenus (souvent de longues citations intégrées au corps du texte), un dispositif d'écriture, basé sur la fiction, l'imagination et l'intuition de l'auteur et des acteurs donne corps à ces citations vives sous la forme d'une succession de plans-séquences comme dans l'écriture cinématographique.

Il apparait alors que l'histoire culturelle telle que la pratique A. de Baecque dans cet ouvrage est très proche du « linguistic turn » américain s'intéressant conjointement, avec Hayden White, aux protocoles linguistiques de l'explication historienne et à la fictionnalité de l'écriture historique. Il s'agit bien de décrire, à l'aide d'une modalité particulière d'écriture historique, les styles et les codes linguistiques qui permettent d'appréhender les configurations des sujets, des objets et des lieux présents dans le champ de perception du rire par la société ellemême. C'est alors qu'A. de Baecque revendique une marginalité de son approche historique : «Le devenir innovant de l'histoire culturelle revient à revendiquer, contre l'académisation actuelle de l'histoire de France, un caractère marginal, périphérique, quasi rebelle mais spécifique » (p. 22). En effet, l'originalité de sa démarche tient à son souci de promouvoir une écriture réaliste, c'est-à-dire qui veut rendre visible l'effet de réel de la représentation qu'une société se donne d'elle-même, évitant ainsi l'invisibilité ordinaire de cet effet de réel au sein de l'écriture métadiscursive de l'historien académique telle qu'elle a été décryptée par Roland Barthes. Dans un climat de professionnalisation, tout particulièrement chez les historiens français de la Révolution française, la démarche d'A. de Baecque s'avère donc particulièrement innovante.

De ce dispositif d'écriture, et des trajets qu'il révèle, retenons ce que la culture des rieurs met en jeu dans un certain usage des mots de la langue française, rejoignant ainsi nos préoccupations d'historien linguiste.

C'est d'abord le «bel esprit» du Régiment de la Calotte qui nous mène, dès le début du siècle, sur une scène comique dominée par « l'inventeur des mots » possédant « l'art légitime du néologisme » à l'encontre de la «légitimation de mots » imposée par le Dictionnaire de l'Académie. À cette "comicratie aristocratique »s'associent des expressions risibles, en " patois de Momus », qui sont insérées dans un rituel, une cérémonie, une procession burlesque, véritable « journée des fastes calotins ", prenant parfois une tournure bien réelle au cours de re- 
pas bachiques où sont distribués des brevets satiriques en présence des militaires fondateurs de la société des calotins. Une question demeure : s'agit-il vraiment d'un pur produit de la réaction culturelle de la noblesse ? L'apport des sources manuscrites, non prises en compte dans cette analyse, peut aboutir tout autrement, comme l'a montré Henri Duranton ( «Quand le rire s'enrégimente : la très joyeuse et très véridique histoire du Régiment de la Calotte », Dixhuitième siècle, 33, 2001) à une filiation non aristocratique avec les moralistes classiques

Dans un second temps, Jean Ramponeau, cabaretier de la Courtille sous l'Ancien Régime, nous introduit dans un tout autre univers comique, celui du corps burlesque investi dans la parade. Après 1750, alors que le cabaret devient lui-même un lieu de parade, la farce peut en sortir pour se déployer sans vergogne du théâtre de foire vers les boulevards. Elle rencontre cette figure si souvent évoquée par les historiens de la presse révolutionnaire, le Père Duchesne, certes d'abord au plus grand profit des royalistes. En effet, ces derniers prennent, massivement en 1790-1791, des travestis populaires pour s'emparer du vulgaire par l'étonnement des sens.

Cependant, toujours après 1750 , la « faction satyrique » redéploie, dans un troisième temps, "le bel esprit» des calotins, mais sous la forme d'un bruyant persiflage contre le sérieux de la langue philosophique des Lumières. C'est le temps des bons mots, de la saillie et de la repartie comme jeu de société. Ces exercices satiriques atteignent leur summum avec la croisade de Rivarol contre «le jargon » et « le baragouin » des révolutionnaires qui ont transformé, d'après lui, les défenseurs de la langue française en ennemis de la nation.

Nous terminons donc ce tour très succinct des genres comiques par «l'emballement linguistique » que l'écriture royaliste met en place contre les mots de la Révolution en inversant leur sens, en les transformant en une caricature d'eux-mêmes. " Guerre de mots » (Brissot) qui devait susciter, dès 1791, la réaction du « grammairien patriote » Urbain Domergue et de ses amis jacobins comme nous l'avons montré dans notre ouvrage sur La langue politique et la révolution française (Meridiens/Klincksieck, 1989). C'est pourquoi A. de Baecque ne fait que mentionner la vaste entreprise des Jacobins pour «mettre la langue à la hauteur de la constitution » contre les pamphlétaires royalistes au point d'arriver à l'éloge d'un laconisme fort éloigné du rire.

Cependant, A. de Baecque continue à rechercher l'appel au comique jusque dans le camp patriote. Il est ainsi entrainé du côté de certains jacobins modérés, fin lettrés toujours sensibles à la gaieté française et son appel au bon sens. Il s'agit d'abord de Cerutti et de la Feuille villa- 
geoise. Ce « philosophe patriote ", convaincu très tôt, du « gai caractère français », défend la voie de «la langue constitutionnaire » comme « langue persuasive » contre « l'idiome exagérateur» des jacobins radicaux. Puis nous sommes entrainé des travées de l'Assemblée Nationale, où sévit successivement un groupe de rieurs aristocrates puis de rieurs patriotes, à la "guerre sarcastique » menée par Gorsas dans son Courrier. La défense par Gorsas, soutenu par Camille Desmoulins, d'un peuple gai, railleur, badaud tourne à l'éloge du processus civilisateur mis en œuvre par la régénération révolutionnaire.

À vrai dire, ces moments de rire ont une part d'impalpable qui les situent à la périphérie de la rationalité linguistique, c'est-à-dire du trajet de « la langue bien faite» (Condillac) des philosophes à la «langue propre » (Sieyès) des législateurs en passant par « la langue du peuple » (Robespierre) des porte-parole jacobins. Certes nous sommes au centre des émotions d'un peuple en révolution, mais nous n'en mesurons les effets comiques qu'au sein d'une récupération politique et antiradicale par le fait de l'instrumentalisation des genres comiques. Fallait-il donc aller plus avant, c'est-à-dire vers les sources manuscrites, là où se trouvent des témoignages d'une punitivité populaire où nous trouvons parfois les traces d'un rire autonome dans sa radicalité même ? Mais c'était alors rencontrer "le comique très féroce », sorte de « comique absolu », de "vrai grotesque » (Baudelaire) qu'A. de Baecque préfère seulement évoquer en conclusion au sein des lectures de la terreur au $19^{\mathrm{e}}$ siècle, alors qu'il était abordé de façon sérieuse au sein même de l'évènement révolutionnaire dans son précédent ouvrage. Nous touchons ici à la limite d'une démarche d'histoire culturelle qui peut hésiter, soucieuse de ne pas se compromettre avec une approche radicale de la violence révolutionnaire, à entrer de plain-pied dans «le rire réflexif » de « la souveraineté punitive » des acteur(e)s de la Révolution française pour n'en retenir que sa régulation ultérieure au sein de la tradition du rire républicain dont nous avons hérité.

Il n'en reste pas moins qu'A. de Baecque a fait le pari que les représentations du rire d'une société par elle-même constitue une part bien réelle de cette société. Nous l'avons suivi dans cette entreprise avec un très grand plaisir tout au long de la lecture d'un ouvrage qui n'a jamais quitté complètement le chemin de « l'esprit de sérieux » et de ses attendus moraux.

Jacques Guilhaumou 